\title{
Effect of green innovation strategy on firm-idiosyncratic risk: a competitive action perspective
}

\begin{abstract}
Despite increasing concern for corporate environmental responsibility in numerous industries, the relationship between green innovation strategy (GIS) and idiosyncratic risk is a rarely scrutinised topic, particularly in the automotive domain. In this study, we empirically explore the association between GIS and idiosyncratic risk and analyse the moderating role played by the firm's competitive action. We rely on the secondary information sourced for 132 top automotive firms, in the period ranging from 2011 to 2017 by applying the system generalised methods of moments estimator to the dynamic panel data model. Our findings indicate that GIS significantly reduces the idiosyncratic risk of all firms, and this relationship strengthens with the increase in the competitive action of the firms. Our evidence supports "it pays to be green" firm heterogeneity argument. This study highlights the academic and managerial implications and focuses on the environmental issues published in environmental management literature.
\end{abstract}

